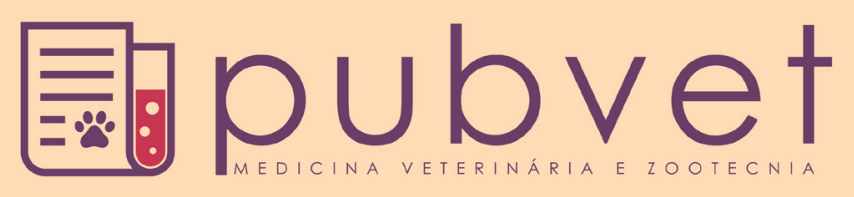

HTTP://DX.DOI.ORG/10.22256/PUBVET.VI1N7.723-726

\title{
Cruzamentos entre a raça Nelore e Bos taurus: um potencial para melhoria do rendimento de carcaça
}

\author{
Felipe Martins Pastor ${ }^{1}$, Fernanda Maria dos Santos de Moraes Falçoni ${ }^{2}$, Diogo Vivacqua \\ de Lima ${ }^{2}$
}

${ }^{I}$ Acadêmico do curso de Medicina Veterinária da Faculdade Multivix - Castelo.felipempastor@gmail.com

${ }^{2}$ Docente do curso de Medicina Veterinária da Faculdade Multivix - Castelo

RESUMO. Com a demanda internacional pelo consumo de carne bovina, surge a necessidade da utilização de técnicas de melhoramento genético que visem um aumento de produção por cabeça. Nesse contexto, a raça Nelore se destaca como uma alternativa eficaz para cruzamentos, sobretudo em criações de regiões tropicais, devido à sua rusticidade, precocidade, alta taxa de ganho de peso. Por possuírem um maior rendimento de carcaça, as raças taurinas são utilizadas como uma das bases para o cruzamento com o Nelore para obter tais características em seus descendentes.

Palavras chave: Grupo genético, produção de carne, taurinos, zebuínos

\section{Crossings between Nellore and Bos taurus: a potential improvement of carcass dressing}

\begin{abstract}
With the international demand for meat consumption, there is a need to use genetic improvement techniques to increase production per head. In this context, Nellore stands out as an effective alternative for crossbreeding, especially in tropical regions, due to its rusticity, precocity and high rate of weight gain. Because they have a higher carcass dressing, bulls are used as one of the bases for crossing with Nellore to obtain such characteristics in their descending.
\end{abstract}

Keywords: Genetic group, Nellore, meat production, taurus, zebus

\section{Cruces entre la raza Nelore y Bos taurus: un potencial para mejorar el rendimiento de la canal}

Con la demanda internacional por el consumo de carne bovina, surge la necesidad de la utilización de técnicas de mejoramiento genético que apunte a un aumento de producción por cabeza. En ese contexto, la raza Nelore se destaca como una alternativa eficaz para cruces, sobre todo en producciones de regiones tropicales, debido a su rusticidad, precocidad, alta tasa de ganancia de peso. Por poseer un mayor rendimiento de canal, las razas taurinas se utilizan como una de las bases para el cruce con el Nelore y obtener tales características en sus descendientes.

Palabras clave: Grupo genético, producción de carne, taurinos, zebuínos

\section{Introdução}

A crescente demanda e a abertura do comércio internacional para a carne brasileira tendem a viabilizar os sistemas de criação intensivos na bovinocultura de corte, já que este oferece uma utilização racional dos fatores de produção (Prado, $\underline{2010}$ ). Fatores como o potencial genético reduzido dos rebanhos de corte brasileiro, a não adaptação 
dos animais aos sistemas de produção em que são inseridos, manejo nutricional deficiente $\mathrm{e}$ carências nos manejos sanitário e reprodutivo, acabam por resultar em uma produtividade reduzida na pecuária de corte(Luchiari Filho, 2000, Prado and Moreira, 2002).

A utilização dos cruzamentos tende a ser uma medida de inclusão da pecuária de corte nacional em um mercado que se configura gradativamente mais competitivo e onde a qualidade da carne é um fator de extrema importância (Rotta et al., 2009). A raça Nelore é a escolhida na maioria das vezes em cruzamentos, tendo obtido ótima aceitação por todo o país, com destaque para a região Sul (Perotto et al., 2009). Reconhecida por sua rusticidade e bom desempenho, mesmo em situações adversas, e com notável precocidade em relação ás outras raças zebuínas, o Nelore também apresenta um maior rendimento de carcaça ao abate, se comparado às outras raças, tanto zebuínas quanto taurinas (Restle, 1999).

Devido à importância da carne bovina na economia nacional, o objetivo desta revisão é demonstrar os principais cruzamentos nos quais a adição do sangue Nelore se torna uma alternativa para a melhora do rendimento de carcaça.

\section{Revisão}

De acordo com Ferreira et al. (2009), a composição genética do rebanho influencia a qualidade final da carne, dependendo das condições alimentares em que os animais forem criados. Lopes et al. (2012) salientam que cruzamentos planejados e executados de forma eficiente tendem a acrescentar de 20 a $25 \%$ na produtividade final dos animais. Para Perotto et al. (2000), os cruzamentos fornecem de forma imediata, benefícios como o aumento do peso e a melhoria da qualidade das carcaças. Os autores ainda evidencia que a razão do sucesso da obtenção de cruzamentos deve-se ao alto nível de heterose existente entre as espécies Bos taurus e Bos indicus.

A utilização de cruzamentos permite combinar características de interesse econômico expressas em diferentes intensidades entre as espécies (Restle, 1999). Como exemplo, pode-se citar o percentual de gordura e uma carne com maior maciez presente nas raças taurinas, enquanto as zebuínas possuem maior rendimento de carcaça. Estudando as características de carcaça de bovinos de corte inteiros ou castrados de diferentes composições raciais Charolês x Nelore, $\underline{\text { Restle et }}$ al. (2000) concluíram que o cruzamento entre as raças produz animais com maior peso de abate, peso de carcaça, rendimento de carcaça, melhor conformação e menor porcentagem de osso na carcaça. Os animais mestiços apresentaram carcaças com melhor conformação do que os da raça Nelore e melhor rendimento de carcaça e grau de acabamento do que o Charolês. Constatações semelhantes foram observadas por Leme et al. (2000). Restle et al. (2000) analisando as características de carcaça e da carne de novilhos de diferentes genótipos de Hereford x Nelore, chegaram à conclusão de que quanto maior grau de sangue Nelore, maior o rendimento de carcaça. Porém, os autores destacam que os animais utilizados no estudo apresentaram carcaças mais leves, e que aumento da proporção de sangue Nelore fez decrescer a maciez da carne não maturada. Com o objetivo de revisar trabalho sobre o desempenho, as características de carcaça, o rendimento de cortes e a qualidade da carne de animais Canchim, Nelore e seus cruzamentos no modelo de criação superprecoce Rotta et al. (2009), relataram bons resultados com os animais cruzados, pois estes possuem alto ganho de peso da raça Canchim, aliado a alta taxa de conversão alimentar apresentada na raça Nelore. Comparando o crescimento e características de carcaça de bovinos superprecoces das raças Nelore, Simental e de seus cruzamentos, e também utilizando o sistema de criação superprecoce, Bianchini et al. (2008) concluíram que os animais oriundos do cruzamento atingem o peso ideal para abate mais rapidamente que animais puros Nelores. De acordo com Leme et al. (2000), os animais obtidos a partir deste cruzamento foram os que apresentaram os maiores pesos de carcaça.

Mourão et al. (2010) observaram que animais oriundos do cruzamento entre Nelore e Limousin apresentam maior espessura do coxão e comprimento dorso-lombo do que as raças puras. Esses dados poderiam sugerir maior rendimento e cortes de maior valor comercial na carcaça dos animais cruzados. Leme et al. (2000) e Jaeger et al. (2004) concluíram que animais F1 Limousin x Nelore são superiores em relação a animais oriundos de outros cruzamentos, no que diz respeito ao rendimento de cortes traseiros. Jaeger et al. (2004) ainda notaram que as carcaças destes animais possuem maior porcentagem de músculo e baixo teor de gordura de cobertura.

Animais resultantes do cruzamento entre Nelore e Red Angus apresentam maior rendimento de carcaça quente, área de Longissimus dorsi, 
segundo os resultados obtidos por Perotto et al. (2000). Estes mesmos animais ainda apresentavam menor percentagens de ossos, e maior de musculatura total na carcaça.A ponta de agulha, segundo Leme et al. (2000) foi o corte de maior destaque obtido com esse cruzamento. $\mathrm{O}$ autor ainda nota que estes animais possuem uma espessura de gordura maior que os outros cruzamentos por ele avaliados.

Aberdeen Angus x Nelore também se destaca como um cruzamento de bons resultados. De acordo com estudos de Souza et al. (2012), esses animais são superiores aos cruzamentos com Simental e ao Nelore puro, no que diz respeito à porcentagem de musculatura na carcaça. Leme et al. (2000) e Jaeger et al. (2004) notaram que os animais deste cruzamento são superiores em rendimento de cortes dianteiros e de ponta de agulha. Quanto ao rendimento de cortes traseiros, os animais não se destacaram o que indicaria uma necessidade de se trabalhar em técnicas de melhoramento genético para os cortes em questão. Leme et al. (2000) ainda analisou o desempenho dos cruzamentos entre Nelore x South Devon e Nelore x Caracu. Estes últimos apresentavam carcaças com ossatura mais leve em comparação aos outros animais. Enquanto isso, os produtos de Nelore x South Devon mostravam superioridade em musculatura total na carcaça e maior rendimento de olho de lombo.

\section{Considerações finais}

Os cruzamentos entre o Nelore e raças taurinas mostram-se como uma ferramenta capaz de aumentar a produtividade do rebanho, tanto em quantidade quanto em qualidade da carne, já que a raça contribui positivamente nesses quesitos.

\section{Referências Bibliográficas}

Bianchini, W., Silveira, A. C., Arrigoni, M. B., Jorge, A. M., Martins, C. L. \& Rodrigues, É. 2008. Growth and carcass characteristics of nellore, simmental and crossbreeds young bulls. Revista Brasileira de Saúde e Produção Animal, 9, 554-564.

Ferreira, J. J., Menezes, L. F. G., Restle, J., Brondani, I. L., Alves Filho, D. C. \& Callegaro, A. M. 2009. Características de carcaça de vacas de descarte e novilhos mestiços Charolês $x$ Nelore em confinamento sob diferentes frequências de alimentação. Revista Brasileira de Zootecnia, 38, 1974-1982.
Jaeger, S. M. P. L., Dutra, A. R., Pereira, J. C. \& Oliveira, I. S. C. 2004. Características da carcaça de bovinos de quatro grupos genéticos submetidos a dietas com ou sem adição de gordura protegida. Revista Brasileira de Zootecnia, 33, 1876-1887.

Leme, P. R., Boin, C., Margarido, R. C. C., Tedeschi, L. O., O'farril, J. C., Alleoni, G. F. \& Albino, L. F. 2000. Desempenho em confinamento e características de carcaça de bovinos machos de diferentes cruzamentos abatidos em três faixas de peso. Revista Brasileira de Zootecnia, 29, 2347-2353.

Lopes, L. S., Ladeira, M. M., Machado Neto, O. R., Paulino, P. V. R., Chizzotti, M. L., Ramos, E. M. \& Oliveira, D. M. e. 2012. Características de carcaça e cortes comerciais de tourinhos Red Norte e Nelore terminados em confinamento. Revista Brasileira de Zootecnia, 41, 970-977.

Luchiari Filho, A. 2000. Pecuária da carne bovina, 1 edn. LinBife, São Paulo.

Mourão, R. C., Rodrigues, V. C., Moustacas, V. S., da Costa, D. P. B., Pinheiro, R. S. B., Figueiredo, M. \& Oliveira Vieira, A. 2010. Medidas morfométricas de novilhos castrados Nelore e F1 Nelore x Limousin. Agropecuária Científica no Semiárido, 6, 27-32.

Perotto, D., Abrahão, J. J. S., Moletta, J. L., Paula, M. C. \& Kuss, F. 2009. Physical composition, primary cuts and meat cuts of carcasses from Zebu and Bos taurus $\times$ Bos indicus crossbred cattle. Revista Brasileira de Zootecnia, 38, 1712-1718.

Perotto, D., Moletta, J. L. \& Cubas, A. C. 2000. Características quantitativas da carcaça de bovinos Charolês, Caracu e cruzamentos recíprocos terminados em confinamento. Revista Brasileira de Zootecnia, 29, 117-124.

Prado, I. N. 2010. Produção de bovinos de corte e qualidade da carne. Eduem, Maringá, Paraná, Brasil.

Prado, I. N. \& Moreira, F. B. 2002. Suplementação de bovinos no pasto $e$ alimentos usados na bovinocultura. Eduem, Maringá, Paraná, Brasil.

Restle, J. 1999. Confinamento, pastagens e suplementação para produção de bovinos de corte. Universidade Federal de Santa Maria. 
Restle, J., Vaz, F. N., Feijó, G. L. D., Brondani, I. L., Alves Filho, D. C., Bernardes, R. A. C., Faturi, C. \& Pacheco, P. S. 2000. Características de carcaça de bovinos de corte inteiros ou castrados de diferentes composições raciais Charolês $\mathrm{x}$ Nelore. Revista Brasileira de Zootecnia, 29, 13711379.

Rotta, P. P., Prado, R. M., Prado, I. N., Valero, M. V., Visentainer, J. V. \& Silva, R. R. 2009. The effects of genetic groups, nutrition, finishing systems and gender of Brazilian cattle on carcass characteristics and beef composition and appearance: a review. Asian-Australasian Journal of Animal Sciences, 22, 1718-1734.
Souza, E. J. O., Valadares Filho, S. C., Guim, A., Valadares, R. F. D., Paulino, P. V. R., Ferreira, M. d. A., Torres, T. R. \& Lage, J. F. 2012. Taxa de deposição de tecidos corporais de novilhas Nelore e suas cruzas com Angus e Simental. Revista Brasileira de Saúde e Produção Animal, 33, 344-359.

\section{Article History:}

Received 16 March 2017

Accepted 11 May 2017

Available on line 13 June 2017

License information: This is an open-access article distributed under the terms of the Creative Commons Attribution License 4.0, which permits unrestricted use, distribution, and reproduction in any medium, provided the original work is properly cited. 